\section{THE NATURE AND TREATMENT OF AMENTIA.}

By Dr. L. Pierce Clark, assisted by the Staff of the Psycho-Analytic Sanatorium at Rye, N.Y.

Ballière, Tindall and Cox. London. 1933.

pp. xvi+306. Price 12s. 6d.

This book approaches the subject of Mental Deficiency from an entirely new standpoint, namely, that of the thoroughgoing Freudian psycho-analyst. For the information of those who are not familiar with them, the first chapter is devoted to a brief outline of the main tenets of this doctrine. This is followed by chapters dealing respectively with the problem of mental arrest, feeblemindedness, secondary amentia, the social behaviour of the ament, the present and future outlook with regard to treatment, and, finally, a short glossary of psycho-analytic terms.

A considerable amount of the book is taken up with a description of patients and an attempt to interpret their amentia in terms of the Freudian doctrine. Thus, whilst admitting that mental arrest may have as its basis inadequate neuronic development, the main thesis of the author is that such a lesion is not the direct cause of the defect, but that it acts by crippling mental development "through its burden of handicap upon the ego and the libidinal processes necessary for mental growth and functioning". A typical example of this point of view is the author's interpretation of the cause of the defect of "Harry", a description of whom occupies twelve pages. Dr. Clark says, "As for his feeblemindedness, we may point to three conditions which seem to have a bearing. First, in passing from the oral ingestion of mother Harry appears to have remained fixed to a great extent upon the taking in of other concrete objects. A wide displacement to the ingestion of ideas, abstract conceptions, understanding, etc., seems not to have taken place. Instead, according to our impressions, the oral grasping is chiefly concerned with candy, physical rewards and presents. Again, his projections towards reality have been seen to be largely on the basis of 'doing things for mother'-that is, for the return to the secondary narcissism rather than for an objective experiencing which may absorb identifications and strengthen the ego's comprehension of reality. Finally, this inability (fear) to voyage into the outer world for a checking of inner concepts has apparently kept him back from fully grasping the nature of the real world."

Whether Dr. Clark's explanation of the cause of Amentia will be regarded as satisfying will, of course, depend upon the reader's view as to the validity of the Freudian hypothesis. Ardent disciples may conceivably regard the book as a useful addition to their knowledge; non-Freudians will probably consider its perusal a waste of time. With regard to treatment, there is no evidence that the various defective children who have been subjected to these psycho-analytical investigations are in any way the better for them-a negative result which would probably be expected by most people with extensive practical acquaintance of the condition.

\section{PSYCHOLOGY AND PSYCHOTHERAPY.}

By William Brown. Third Edition.

London : Edward Arnold \& Co. 1934.

Pp. vi. +252 .

12/6d.

The third edition of Dr. Brown's Psychology and Psychotherapy, which has just been published, has been so thoroughly revised and amplified that it is practically a new book. It is concerned more with psychotherapy than with psychology, as is obvious from the titles of the chapters-the present importance of psychology and psychotherapy, dissociation, multiple personality, dreams, the unconscious, theories of emotion, the psycho-neuroses of war, the psychotherapeutic treatment of alcoholism, adolescence suggestion, hypnotism, faith, personal influence, the psychology of peace and war, the relation of mind to brain, and psychical research. The style is popular and personal, for it abounds in references to the author's own practice and experience. It is more than a series of essays on psychotherapy written in popular language for the physician and the layman; it ranges over the fields of psychology, psychotherapy, philosophy, religion and psychical research, and conveys to the reader much of his philosophy of life, for Dr. Brown is a 